\section{The therapeutic benefit of music during ECT treatment}

\section{DeAR Sirs}

We have on a small scale investigated the effect that playing music has on patients during the administration of ECT. This was carried out over a period of two months with a group of patients receiving twice weekly ECT.

Music was played only on one of these twice weekly treatments. During this time a great majority of the patients receiving treatment, in fact over two-thirds of them, stated that they found the music very soothing. This calming effect was most beneficial at both induction of and recovery from anaesthetic.

We wondered if any studies have been done in this area to assess the therapeutic benefits music might have on patients undergoing ECT. Any further information on the subject will be welcome.

J. Almeida

P. TAPANG

The London Hospital

London E3

\section{Borderline states}

DeAr Sirs

At the recent annual meeting at the Royal College of Psychiatrists a session on borderline states was advertised. It seemed that the College was arranging a forum in which the concept of borderline states would be discussed. Unfortunately this was not the case. Instead the session, which featured some distinguished speakers, concentrated on schizophrenic and schizotypal disorders. This is not in keeping with current views on borderline states.

Borderline states have had a chequered career, but a review of the literature shows the concept has two main roots-one is founded within a general psychiatric framework whilst the other has developed within psychoanalytic thinking. These have given rise to four approaches: a research orientated approach, typified by the work of Gunderson and Kolb; ${ }^{1}$ a psychodynamic approach, developed by Kerberg ${ }^{2}$ and others; a genetic approach trying to ally borderline conditions within the genetic spectrum of schizophrenia; ${ }^{3}$ and a view that borderline states represent a subgroup of affective disorders. ${ }^{4}$ It is, then, surprising that these views were not represented at the College session.

I am not privy to College processes but it seems, at the very least, narrow-minded to arrange such a session and then merely focus on one aspect. Indeed, the psychodynamic approach was placed on its own in the psychotherapy specialist section. Why should this be so? Surely the concept of borderline states, rooted as it is in psychoanalytic work and general psychiatry, is a golden opportunity for these different approaches to join together in trying to understand a difficult and contentious area. The College appears to have missed this opportunity and I hope they will rectify the error in the future by presenting a more balanced educational programme.

ANTHONY W. BATEMAN

Whittington Hospital

Highgate Hill, London N19
REFERENCES

'Gunderson, J. \& Kolb, J. (1978) Discriminating features of borderline states. American Journal of Psychiatry, 135, 792.

2KERnBerg, O. (1967) Borderline personality organization. American Journal of Psychoanalysis, 15, 641.

${ }^{3}$ KeTY, S., et al (1975) Genetic Research in Psychiatry. New York: Johns Hopkins University Press.

${ }^{4} \mathrm{KLEIN}, \mathrm{D}$. (1975) Psychopharmacological treatment and delineation of borderline disorders. In Borderline Personality Disorders: The Concept, the Syndrome, the Patient (ed. P. Hortocollis). New York: International Universities Press.

\section{British psychiatrists in Canada}

DeAR Sirs

It was interesting to read G. M. Green's article about British psychiatrists in Canada (Bulletin, April 1985, 9, 77-78). I would like to shed more light on the difficulties faced there as a result of my own experience.

In recent years many jobs for psychiatrists have come up, mostly advertised in British journals, and many psychiatrists in Britain have been appointed to these jobs. At the time of appointment a 'Special Licence' is issued and very little is explained about this. Practice is restricted to an institution which is likely to be in a remote area where Canadian-trained psychiatrists do not want to work. A move from there to another hospital or to private practice requires a 'General Licence' which requires the LMCC and FRCP(C) in psychiatry.

The 'Special Licence' produces considerable difficulties: it excludes one from working in private practice, legal work, or becoming attached to a teaching hospital. Since the standard of psychiatry varies widely across Canada, and isolated places have hospitals which are inferior to those in the big cities, one virtually becomes a second-class clinician.

The financial gains may appear to be good on paper (these are usually in excess of 70,000 Canadian dollars), but when it comes to what is left in your pocket after expenses, it is a different story. The cost of living also varies widely across Canada. The price of food and other necessities is at least two to three times higher in isolated areas than in cities such as Toronto or Montreal.

If one decides to take the $\mathrm{FRCP}(\mathrm{C})$ exam in psychiatry and proceed to a 'General Licence', one is faced with additional difficulties. In most cases, the Canadian Royal College of Physicians requires that candidates spend one to two years in a training programme in Canada before being eligible to sit the exam. There are only 13 training programmes at University level, each with only a limited number of positions for residents. Most of the programmes are reluctant to take someone for one year only; they prefer trainees to spend a whole four years in a teaching programme and have internship in North America prior to that.

For all these reasons it is advisable to consider carefully taking up a position in Canada on the basis of a 'Special Licence'.

Bloomfield Hospital

ISHRAT ALI

Orange, NSW, Australia 